\title{
Percent Recovered from T1 to T2 Normalized by Surface Area
}

National Cancer Institute

\section{Source}

National Cancer Institute. Percent Recovered from T1 to T2 Normalized by Surface

Area. NCl Thesaurus. Code C102384.

The percentage of the administered dose that is recovered from the specimen type specified in PPSPEC, over the interval between T1 and T 2 divided by surface area. 